of $2-3 \mathrm{~mm}$ as shown in the UK small aneurysm trial. ${ }^{11}$ The repeatability of the scan improved if operators' performance was checked regularly. In the Gloucestershire project a single scan only was required for $95 \%$ of the county, and the authors suggest that gradual introduction of increased elective surgery in men over 65 years old would extend surgical workload by a manageable amount. However, if all men over 65 were suddenly screened, vascular services would be overwhelmed.

Screening of patients with peripheral arterial disease in the United States-"legs for life"-has suggested that $25 \%$ of participants are at risk of ruptured abdominal aortic aneurysm. To screen patients with atherosclerotic disease, rather than the whole population, is more cost effective, ${ }^{12}$ just as it is to leave out women altogether, for which political consideration is needed.

The multicentre aneurysm screening study and the Gloucestershire project used criteria from the UK small aneurysm trial to determine which patients should be operated on (aneurysm $>55 \mathrm{~mm}$ in diameter, tender, or growth $>10 \mathrm{~mm}$ per year). Recent data from Brady et al about to be published in Circulation indicate that smokers have a faster rate of aortic aneurysm expansion, and we anxiously await the results of the endovascular aneurysm repair trials to learn if endovascular repair carries a lower risk of mortality than open repair and at what cost. ${ }^{13}$ This could influence the enthusiasm for the adoption of national screening but should not be a factor on its own.

If the useful pilot in Gloucestershire were reproduced nationally, the cost could be less than $£ 50 \mathrm{~m}$ per year, and ruptured abdominal aortic aneurysm could become a national rarity. What a boast for the NHS that would be. It would put an end to the middle of the night dramas with ruptured abdominal aortic aneurysm, and the attendant high costs in blood products, medical and nursing staff at night, and long stays in intensive care. The future could be a properly resourced national screening programme with gradual reduction of surgery for ruptured aortic aneurysm, with its attendant strains on patients' relatives, as well as a reduction in the strain on hospital resources and in the antisocial hours that doctors and nurses are required to work, often against the thrust of the European Working Time Directive.

\section{Roger M Greenhalgh professor of surgery}

Imperial College of Science, Technology, and Medicine, Charing Cross Hospital, London W6 8RF

Competing interests: RG was the lead applicant of the UK small aneurysm trial (funded by the Medical Research Council and British Heart Foundation) and the UK endovascular aneurysm repair trials (funded by the NHS R\&D Health Technology Assessment) and a recent board member of the MRC.

1 Law MR, Morris J, Wald NJ. Screening for abdominal aortic aneurysms. J Med Screen 1994;1:110-6.

2 Brown LC, Powell JT. Risk factors for aneurysm rupture in patients kept under ultrasound surveillance. Ann Surg 1999;230:289-97.

3 Multicentre Aneurysm Screening Study Group. The multicentre aneurysm screening study (MASS) into the effect of abdominal aortic aneurysm screening on mortality in men: a randomised controlled trial. Lancet 2002;360:1531-9.

4 Multicentre Aneurysm Screening Study Group. Multicentre aneurysm screening study (MASS): cost effectiveness analysis of screening for abdominal aortic aneurysms based on four year results from randomised controlled trial. BMJ 2002;325:1135-8.

5 Irvine CD, Shaw E, Poskitt KR, Whyman MR, Earnshaw IJ, Heather BP. A comparison of the mortality rate after elective repair of aortic aneurysms detected either by screening or incidentally. Eur J Vasc Endovasc Surg 2000;20:374-8.

6 Greenhalgh RM, Powell JT. Screening men for aortic aneurysm. BMJ 2002;325:1123-4.

7 Gray JAM. Screening for abdominal aortic aneurysm. Br J Surg Gray JAM. Screet.

2003;90:1165.
Curtis S. Human cost should not be dismissed. BMJ 2003;326:284

9 Earnshaw JJ, Shaw E, Whyman MR, Poskitt KR, Heather BP. Screening for abdominal aortic aneurysms in men. BMJ 2004;328:1122-4.

10 Ellis M, Powell JT, Greenhalgh RM. Limitations of ultrasonography in surveillance of small abdominal aortic aneuryms. $\mathrm{Br}$ J Surg 1991:78:614-6.

11 UK Small Aneurysm Trial Participants. Mortality results for randomised controlled trial of early elective surgery or ultrasonographic surveillance for small abdominal aortic aneurysms. Lancet 1998:352:1649-55.

12 Spurgeon D. US screening programme shows high prevalence of aortic Spurgeon D. US screening pro
aneurysm. BMJ 2004;328:852.

13 Brown LC, Epstein D, Manca A, Beard JD, Powell JT, Greenhalgh RM. The UK endovascular aneurysm repair (EVAR) trials: design, methodology and progress. Eur J Vasc Endovasc Surg 2004;27:372-81.

\title{
Assisted suicide
}

\section{We need to clarify the current legal compromise but preserve the lenient attitude}

$\mathrm{T}$ The existing law on assisted suicide is contradictory, confused, and opaque. We need to take a fresh look at this issue and perhaps preserve the essence of the compromise that the courts tacitly favour.

Retired general practitioner Michael Irwin was recently investigated in the Isle of Man, for allegedly conspiring to assist the suicide of his friend Patrick Kneen. ${ }^{1}$ Irwin reportedly intended to provide a large dose of sleeping pills. Patricia, Mr Kneen's wife, was also investigated. In the event, neither was charged, which was surely a relief to both, given the prospect of a maximum prison sentence of 14 years, as would also be the case in England and Wales, under the Suicide Act 1961. The timing was arguably unfortunate, since the Manx Parliament (the House of Keys) is considering permitting voluntary euthanasia, a reform that Mr Kneen himself advocated publicly.
Our law lords have also recently contemplated-but rejected-both a similar proposal from Lord Joffe and the application by Diane Pretty. ${ }^{2-4}$ Mrs Pretty, who had motor neurone disease, sought an assurance that her husband would not be prosecuted should he assist in her suicide. Both our courts and the European Court of Human Rights denied that the right to life encompassed a right to choose the timing and manner of one's death. The judges also felt that any arguments premised on respect for patients' autonomy were outweighed by the state's interest in preserving life and protecting the vulnerable.

Diane Pretty's challenge and Lord Joffe's bill had the backing of the Voluntary Euthanasia Society, of which Irwin was chairman until the recent investigation. This is not the first time that one of its key personnel has allegedly breached the criminal law: the conviction of Nicholas Reed, the society's former 
general secretary, for assisted suicide prompted the organisation to change its name from EXIT, in order to distance itself from his activities. ${ }^{5}$ Then as now the organisation clearly stated that it does not condone operating outside the law, although it does seek a change in the law.

Surely a case is to be made for reform, but not along the permissive lines that have been proposed, including those in a controversial editorial in this journal. ${ }^{6}$ Rather, what is needed is greater clarity in the definition and application of the offence. The prosecutions to date in England and Wales show a body of law that is replete with uncertainty, obfuscation, and injustice.

Consider the "classic" case of "leaving the pills." Certainly convictions have been made in such circumstances, but this does not explain why one case was dismissed by the court since the accused "only provided the option," which was, said the judge, "not enough."” Furthermore no health professional has been prosecuted for the offence in this jurisdiction despite at least anecdotal evidence indicating that such assistance does occur. ${ }^{8}$

No less confusing is the (il)legality of "death tourism." After Reginald Crew was assisted to die in Switzerland, uncertainty prevailed over whether his wife, Win, had committed an offence in helping him to travel there. Although the police declined to prosecute in that case, they have yet to promulgate their prosecuting policy on this issue.

Perhaps most objectionable, however, is a ruling reported in 1989. Mr and Mrs Johnson were convicted of assisting the suicide of their daughter Sara (who also had motor neurone disease) after she had taken an overdose. They did nothing positively to assist Sara: as the judge said they were guilty of "purely negative conduct" in sitting with her and honouring her request not to summon medical intervention. ${ }^{9}$

That conviction is problematic for at least three reasons. Firstly, it implies that one must not inform one's close friends or relations as to any suicidal intent for fear of exposing them to criminality. That hardly sits well with the intentions behind the suicide bill, where it was stated that suicidal people should be dealt with compassionately (hence its decriminalisation). ${ }^{10}$ Secondly, supporters of the bill believed that the offence would require some "clear, positive element," so the Johnsons' convictions again seem to frustrate parliamentary intention.

But finally, and perhaps most importantly, in the healthcare context the conviction conflicts with the assumed validity of a patient's refusal of treatment, whether made contemporaneously or in advance of incompetence. Provided of course that Sara was competent (and perhaps that was the sticking point), she seemingly should have enjoyed the same rights as were successfully asserted by ventilator dependent Ms B. ${ }^{11}$ Yet, while Ms B's trust was found liable in damages for violating the principle of respect for a patient's autonomy and thereby trespassing against $\mathrm{B}$, the Johnsons were found guilty for honouring that principle. What is the basis for the distinction? Is it simply because the Johnsons were not health professionals in a healthcare setting? Are advance directives valid only in such a context?

A case exists, at first sight, for a fresh look at this area. The current law rightly adopts a compromise between the more extreme "right to die" and right to life positions, as seen in those lenient sentences passed down on those (usually "mercy killers") convicted of the offence. Nevertheless, greater clarity is needed both here and in other aspects of the law governing the end(ing) of life. ${ }^{12}$ The best approach might be to heed recent calls for an investigation by a new House of Lords Select Committee or Royal Commission. Quite what shape the law will ultimately take remains to be seen; what should be clear, however, is that a review is desperately needed.

Richard Huxtable lecturer in medical law and ethics

Centre for Ethics in Medicine, University of Bristol, Bristol BS2 8BH (R.Huxtable@bristol.ac.uk)

\section{Competing interests: None declared.}

1 Wainwright M. Arrested euthanasia society chief resigns. Guardian 2003 15 December: 11

Lord Joffe. Patient (assisted dying) bill (HL). wwwpublications. parliament.uk/pa/ld200203/ldbills/037/2003037.pdf (accessed 28 Jan 2003).

$3 \mathrm{R}$ (on the application of Pretty) $v$ DPP [2002] 1 FLR 268 (House of Lords).

4 Application No 2346/02 Pretty $v$ UK (2002) 35 EHRR 1 (European Court of Human Rights)

5 EXIT campaigner gaoled. Guardian 198131 October:1, 4.

Doyal L, Doyal L. Why active euthanasia and physician assisted suicide should be legalised. BMJ 2001;323:1079-80.

7 Gorman F Teenager cleared of aiding suicide. Times 199323 September:3.

Nonton C. Family doctors a it helping thousts of patents to die. Sunday Times 199815 November:2. Probation for parents who watched their daughter die. Independent 198 18 November: 3 .

10 House of Commons. Parliamentary debate (Hansard). 196114 July;644: col 837.

1 Re B (Adult: Refusal of Medical Treatment) [2002] 2 All ER 449.

12 Huxtable R. Get out of jail free? The doctrine of double effect in English law. Palliat Med 2004; 18: 62-8.

\section{Physical activity and coronary heart disease}

\section{Fifty years of research confirms inverse relationship}

$\mathrm{F}$ ifty years ago the first empirical investigation of what was subsequently termed the exercise hypothesis-physical activity reduces the occurrence of coronary heart disease-was undertaken by Morris et al. ${ }^{1}$ Using data from two cohorts of British workers, they reported lower rates of coronary heart disease in bus conductors than in less occupationally active bus drivers, and in postmen relative to deskbound telephonists and other office based employees. Although this research was pioneering, it was not without its shortcomings. Early statistical methods were limited in their capacity to explore the issue of confounding-for example, it was possible that higher levels of overweight, high blood 